\title{
Stacked: In Their Favour? The Complexities of Fuel Stacking and Cooking Transitions in Cambodia, Myanmar, and Zambia
}

\author{
Martin Price ${ }^{1, *(\mathbb{D})}$, Melinda Barnard-Tallier ${ }^{1,2} \mathbb{D}$ and Karin Troncoso ${ }^{3}$ \\ 1 Gamos, Reading RG1 4LS, UK; melinda@gamos.org \\ 2 Department of Anthropology, University of the Witwatersrand, Johannesburg 2000, South Africa \\ 3 Geography and Environment, School of Social Sciences and Humanities, Loughborough University, \\ Loughborough LE11 3TU, UK; k.s.troncoso@lboro.ac.uk \\ * Correspondence: martin@gamos.org
}

check for updates

Citation: Price, M.; Barnard-Tallier, M.; Troncoso, K. Stacked: In Their Favour? The Complexities of Fuel Stacking and Cooking Transitions in Cambodia, Myanmar, and Zambia. Energies 2021, 14, 4457. https:// doi.org/10.3390/en14154457

Academic Editor: Brent S. Steel

Received: 25 May 2021

Accepted: 21 July 2021

Published: 23 July 2021

Publisher's Note: MDPI stays neutral with regard to jurisdictional claims in published maps and institutional affiliations.

Copyright: (c) 2021 by the authors. Licensee MDPI, Basel, Switzerland. This article is an open access article distributed under the terms and conditions of the Creative Commons Attribution (CC BY) license (https:/ / creativecommons.org/licenses/by/ $4.0 /)$.

\begin{abstract}
It remains unclear whether the decision to cook with both polluting and cleaner-burning fuels ('fuel stacking') serves as a transition phase towards the full adoption of clean-cooking practices, or whether stacking allows households to enhance fuel security and choose from a variety of cooking technologies and processes. This paper offers a unique contribution to the debate by positioning fuel stacking as the central research question in the exploration of existing household survey data. This research analyses the World Bank's Multi-Tier Framework survey data concerning energy access and cooking practices in Cambodia, Myanmar, and Zambia. Its novel approach uses fuel expenditure data to group urban households according to the intensity of biomass consumption (wood, charcoal) relative to modern fuel consumption (electricity, gas). The research explores how different fuelstacking contexts are associated with factors related to household finances, composition, experiences of electricity, and attitudes towards modern fuels. This study shows the diversity of characteristics and behaviours associated with fuel stacking in urban contexts, thus demonstrating the need for fuel stacking to feature prominently in future data collection activities. The paper ends with five key recommendations for further research into fuel stacking and its role in clean-cooking transitions.
\end{abstract}

Keywords: fuel stacking; clean cooking; electric cooking; urban; culture; perceptions; Cambodia; Myanmar; Zambia

\section{Introduction}

It has been widely documented that almost 3 billion people worldwide rely on polluting fuels (e.g., wood, charcoal, kerosene) to meet their cooking needs [1]. However, in 'The State of Access to Modern Energy Cooking Services' report, published in 2020, this number is reported to be as high as 4 billion people [2]. The use of solid fuels and kerosene leads to high levels of household air pollution (HAP), resulting in negative impacts on health, environment, well-being, and climate [3]. Unsustainable harvesting and production methods, as well as inefficient household fuel combustion, result in significant greenhouse gas and black carbon emissions, contributing to global and regional climate change respectively [Ibid]. Substituting polluting fuels with cleaner-burning fuels such as liquefied petroleum gas (LPG) or electricity has the potential to mitigate these negative outcomes [4].

"Clean fuels", according to the World Health Organisation (WHO), are fuels with emissions that result in a CO exposure level of less than $7 \mathrm{mg} / \mathrm{m}^{3}$ and a $\mathrm{PM}_{2.5}$ level of less than $10 \mu \mathrm{g} / \mathrm{m}^{3}$ over a prolonged period of time [5]. These guidelines are based on assessments of the health consequences of exposure to $\mathrm{PM}_{2.5}$ and $\mathrm{CO}$, and on the maximum permissible levels of these compounds in the air inside homes for a healthy environment. At present, the fuels that achieve clean fuel status according to these measures are electricity, gas, ethanol, and biogas. However, it is acknowledged that to be considered truly clean, fuels must also be generated from renewable sources. The extent to which LPG as a fossil fuel should feature in clean-cooking transitions is widely debated [6]. 
Clean-cooking transitions are often understood through the concept of the 'energy ladder': a linear model that suggests the use of 'dirty', or polluting, fuels decreases as economic status increases (Figure 1). The rationale behind the energy ladder is that once an individual or household can access and afford a clean fuel, they will choose to switch their cooking practices to enjoy the benefits of clean cooking, which range from increased efficiency and convenience to improvements in health outcomes.

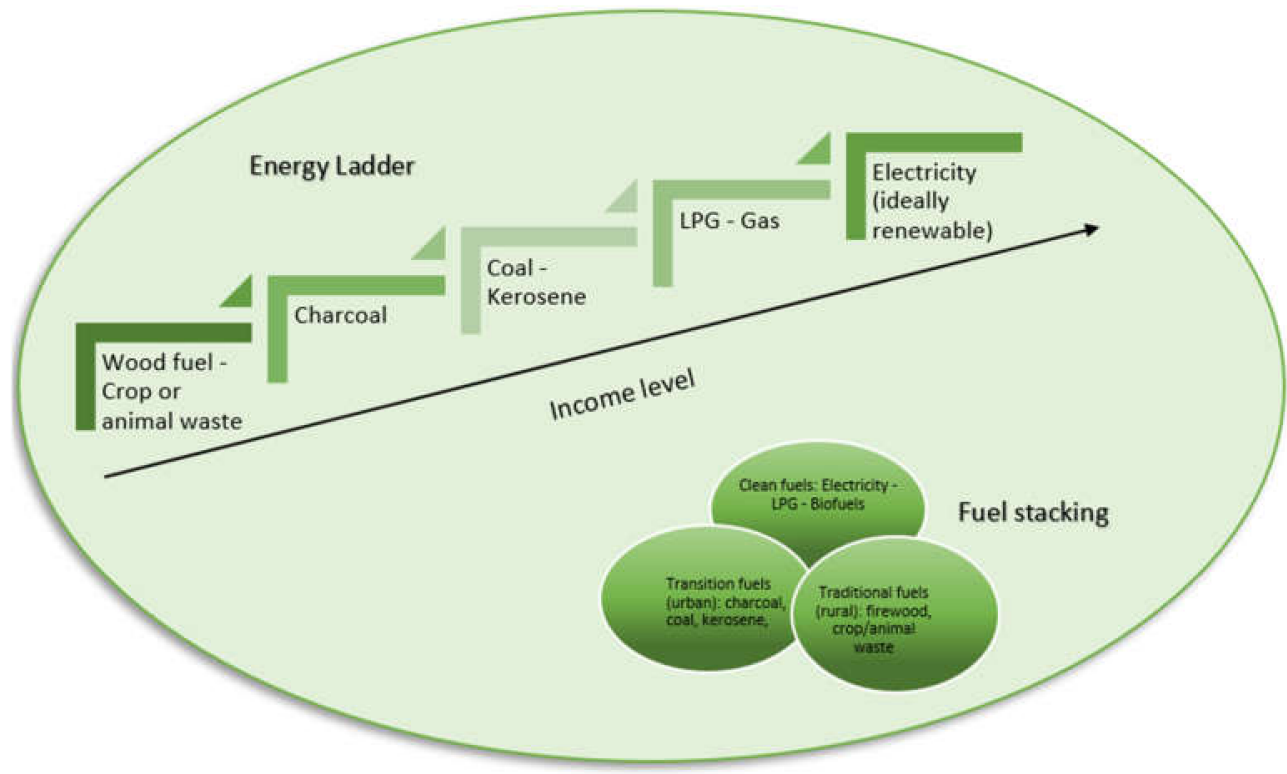

Figure 1. The energy ladder and fuel-stacking models (Authors' own).

However, clean-cooking transitions are not always linear. The introduction of new fuels and technologies does not mean the complete abandon of other fuels, resulting in what scholars refer to as fuel stacking [7], see also [8-10]. Fuel stacking can often be misunderstood as an interim phase of transition as households continue to use polluting fuels until they have sufficiently familiarised themselves with cleaner fuels and technologies. Rather, fuel stacking can often be an end in itself, providing households with fuel security and the flexibility to meet a range of cooking needs. As Shankar et al. [11] have recently argued, "everybody stacks" and yet little is known about the implications of fuel stacking on public health and the environment, or how a transition towards cleaner stacking can be achieved. As the idea of a clean fuel stack gains traction within the clean-cooking sector, to meet sustainable development goals and household needs relating to fuel security and flexible cooking practices, more research is needed to understand (a) the dynamics of fuel stacking and (b) how modern energy cooking technologies can integrate within different kinds of fuel-stacking practices.

This paper investigates how the characteristics of fuel-stacking households vary across different national and regional contexts. This intervention combines a thorough review of qualitative studies into fuel stacking with an exploratory quantitative analysis of the World Bank's Multi-Tier Framework (MTF) data for Cambodia, Myanmar, and Zambia. The data was disseminated through three country-specific reports [12-14], which present only a brief overview of fuel-stacking practices in each of the three countries. After weighting the data, these reports suggest fuel stacking occurs in approximately half of Zambian households, a third of Cambodian households, and a tenth of Myanmar households, but no further insights are provided. By contrast, this comparative, mixed-methods, and interdisciplinary approach to desk-based research reveals that fuel-stacking practices are both complex and context-dependent. As a result, this paper argues that place-based research is vitally important to unlocking and accelerating clean energy and clean-cooking transitions, and to understanding the role that fuel stacking plays in achieving transition 
objectives pertaining to health, safety, and the environment. The analysis below provides a window into the dynamics of fuel stacking in these different contexts, and this research can help policymakers and practitioners review the role of fuel stacking in localised cooking fuel transitions. Therefore, this analysis also offers a critique of existing data collection methods akin to the MTF surveys, highlighting the limits of quantitative methods when they are removed from local contexts and more nuanced patterns of human behaviour. This study highlights the need for fuel stacking to be treated as a research problem in its own right, and to be featured explicitly in surveys and questionnaires that inform targeted clean-cooking interventions.

This research focuses specifically on fuel stacking among urban populations in the three focus countries. Although market-based approaches currently hold widespread appeal across the renewable energy and clean-cooking sectors [15], it is with respect to urban populations that an economic rationale of cooking transitions is most often applied [16]. Urbanisation is associated not only with higher average incomes, but also with greater access and availability of cleaner fuels and technologies. Thus, progression up the energy ladder is seen as more feasible-perhaps even inevitable-in urban areas compared to rural areas. However, fuel stacking remains prevalent among urban populations [11,17]. Little is known about fuel stacking in either urban or rural contexts, and this paper provides insight into the former to further the fuel-stacking debate and encourage the clean-cooking sector to place stacking-related concerns at the forefront of its interventions.

This paper proceeds with an exploration of factors that explain fuel stacking and the persistence of biomass in urban contexts, drawing predominantly on qualitative studies related to cooking and fuel choice. With this review of the literature in mind, the paper then analyses the MTF data for urban populations in Cambodia, Myanmar, and Zambia and demonstrates the complexity and contextual specificity of factors associated with fuel-stacking practices. This paper shows unequivocally that fuel stacking is a diverse set of practices that are widespread in urban areas of these three countries. To transition households to cooking exclusively with modern fuels, the clean-cooking sector needs to engage in situated realities and explore how stacking behaviours relate to cultural, economic, and policy landscapes in a given context. Recommendations for further research are provided towards the end of the paper.

\section{What Explains Fuel Stacking?}

This section reviews a wide range of qualitative studies that explore the reasons why fuel stacking is practiced, and specifically why the use of biomass-fuelled stoves persists in contexts where modern energy alternatives are available to consumers. Combining fuels can involve a wide range of cooking practices that will change from place to place, and the reasons for fuel stacking are likely to be multiple, nuanced, and attached to individual contexts. Therefore, this section directly informs the analysis and subsequent discussion of the MTF data, presented later in the paper.

A focus on fuel stacking, rather than on linear fuel transitions, requires a shift in perspective. If it is assumed that all cooking fuels and devices have their own benefits and limitations, then innovations in modern fuel technologies have the potential to deliver ever-increasing benefits to the household. For instance, gains in energy efficiency may reduce cooking times and the financial cost of cooking, and the cost of the technologies themselves may reduce over time as supplementary innovations come on to the market. Under such circumstances, biomass-fuelled stoves become less and less desirable relative to the alternatives.

However, the partial adoption of modern fuel technologies can also have the effect of minimising the limitations of biomass-fuelled stoves. Despite the health risks and the inconvenience of lighting biomass-fuelled stoves, the practice of fuel stacking gives households the opportunity to spread the cooking load across multiple devices, and use biomass for specific types of meal preparation, such as for special occasions, or for cooking for larger groups. If some benefits to biomass cooking persist regardless of how modern 
fuel technologies evolve, it is likely that fuel stacking will continue to be popular for many households with access to a range of fuels and devices.

When it comes to fuel choices, health concerns are frequently overshadowed by other priorities related to food security and finances. Even when clean fuels are heavily subsidised [18], a subset of households continue to rely on traditional stoves and fuels to meet some of their cooking needs. In urban spaces, research has found that initial costs around fuel and cooking system transitions is a major barrier [19-24]. However, despite acknowledging that ongoing fuel costs might be reduced or unchanged when transitioning, respondents in Jewitt et al.'s [23] study of cooking system usage in Benue, Nigeria, explained that financial constraints and need for expenditure elsewhere made end users sceptical about investing upfront. Households-even those in urban spaces where average salaries are more substantial and dependable-prioritise property rents, and education and transport costs. Such concerns will be analysed later in the paper with respect to the MTF survey data.

As the cost of charcoal rises across much of urban Africa and Asia, and as gains in battery storage and the efficiency of electric cooking continue at pace [25], it remains to be seen whether these dynamics are sufficient to thwart fuel-stacking practices. Related to this issue, several scholars have pointed to non-financial factors that explain the continued use of biomass. Jewitt et al. [23] found that smoke is seen to be useful in the preservation of food in the absence of fridges and reliable/affordable electricity, and smoke additionally wards off mosquitoes. People cooking with wood also claimed that food cooked faster (necessary when shift workers return home for a quick meal) due to the belief that adding more wood increases heat quickly [26,27]. Although concerns around speed and taste may be mitigated by altering either the electrical appliance or adapting the cooking technique [27], this highlights the complexity of perception that is deeply embedded in the culture of cooking. Jewitt et al. [23] also found that respondents felt that transitions that required a change to the technique of cooking were resisted if they were deemed to be culturally inappropriate (see also [28,29]). Decision-making is also culturally embedded within gender norms, with women often being responsible for fuel collection and the labour of cooking, but quite often are removed or absent from the decision-making processes around fuel use and adoptions.

Ruiz-Mercado et al. [9] note that kitchens are cooking systems that entail many tasks, which are hard to fulfil using a single device. The need for pots that accommodate larger households is important and studies have shown that users feel that clean-cooking solutions did not always take this into consideration [23]. Although it would be assumed that this was only the concern of larger households, it was found that even smaller households who initially transitioned to clean-cooking solutions would revert to biomass fuels as their family/household grew. Stacking was found to be favourable in that the person tasked with cooking could prepare multiple dishes at the same time, and that there was a concern that dishes cooked in new / alternative ways would be rejected based on not keeping within traditional cooking practices.

A preference for multiple stoves and devices is not just a reflection of how many people to cook for; large meals often hold enormous cultural significance. In ethnicities where elevated socio-economic status is linked to the ability to cook large quantities of food [29], this is not a trivial concern and perceptions of the community hold high value in terms of one's own social capital [30,31] or cultural capital [32]—these being imperative in enabling (or preventing) social mobility within a community. These social ties do not necessarily end with a move to the city, as shown in an ethnographic study of cooking practices and cooking fuel choices in an urban slum in Kampala, Uganda [33].

Furthermore, studies have shown that concerns around the safety of new technologies increases resistance to adopt cleaner cooking systems [19,20,23,24,34,35]. Often resistance to learning a new technology is put forward as a barrier, but studies have found that incorporation of new technologies raises other anxieties: structural alterations to the home to include clean-cooking solutions, maintenance and initial investments were put forward as barriers to uptake [36-38]. Additionally, cultural barriers around gender 
mixing — such as not wanting unknown men to be alone with women during installation or maintenance-has been noted elsewhere [39].

Other gender-based claims within energy transitions also need to be analysed more critically. Arguments for a full transition to modern fuels are often embedded in strategies focused on reducing gender-based violence, reducing drudgery, and freeing up time. Winther [27] reports that women in Uroa, Zanzibar, in fact found that electrification had the effect of speeding up the daily pace of life to such an extent that women reported having too little time for some tasks. Participants in Winther's [27] research particularly referenced cooking as an example of what had been lost: where they had previously cooked three meals a day, they now only cooked two. It is imperative to understand the socio-cultural and practical reasons why households might not be willing to fully transition to clean cooking even when issues of access and affordability are absent [40]. Additionally, this might go a long way to understanding why households that do transition often revert to using prior fuels and systems, as is often observed.

Finally, it is important to acknowledge how the widespread use of polluting fuels may be explained by influences outside of individual households. For instance, Haysom et al. [41] investigate the illicit charcoal markets which operate in Kenya, Uganda, and South Sudan. Charcoal dealers often have links to government officials who facilitate the flow of charcoal within these markets for a 'fee' and thus keep these markets in operation. These markets in turn have both direct and indirect influence on processes of adoption and transition through power and influence. We note, here, that further research is needed to understand the full impact these markets have on fuel pricing, availability, and user transition choices.

This review of the literature shows that a wide range of factors can be used to explain fuel stacking and the persistence of biomass stoves in contexts where cleaner alternatives are available. Such practices allow users to benefit from different fuels and technologies either using each one for the task that it best performs, or by stacking multiple fuels to increase energy security. This strategy also helps households to be more resilient to an uncertain changing economic or climate context [42]. The extent to which fuel stacking is part of the solution for the clean-cooking sector depends on the extent to which polluting fuels continue to be used for cooking, the sustainability of biomass industries, and the ways in which these fuels are used (indoors/outdoors, the type of stove used).

\section{Materials and Methods}

This paper uses household survey data from Cambodia, Myanmar, and Zambia to investigate the characteristics of fuel-stacking urban households in these respective countries. Although the previous section highlighted some of the reasons why fuel stacking persists in certain contexts, large-scale surveys provide an opportunity to identify a broader context to fuel stacking, and how fuel-stacking households differ from those that cook exclusively with either biomass or modern fuels. The survey data used in this research is public access and forms part of the World Bank's MTF approach to energy access. The MTF takes account of the multidimensionality of energy access and access to modern energy cooking services. In other words, access is not reduced to a simple binary (with access/without access) but is instead understood as a series of tiered systems that relate to issues of availability, reliability, affordability, safety, and so forth. The World Bank's Energy Sector Management Assistance Programme (ESMAP) has produced country-specific diagnostic reports [12-14] that showcase the multidimensionality of access to energy, with a section dedicated to energy for cooking. Building on this work, the Modern Energy Cooking Services (MECS) Programme has conducted analysis of the MTF survey data in these three countries [43-45] to explore how electricity access and clean-cooking solutions relate to one another, as the official diagnostic reports only consider these two themes in isolation.

This paper goes one step further and presents analysis that focuses more acutely on fuel-stacking households residing in urban areas. Households that label themselves as 
rural are excluded for the following reasons: (a) their choice of fuels are more likely to be limited; and (b) they are more likely to have access to free collected firewood. The focus on urban households involves another level of disaggregation of the data, to allow households in Phnom Penh (Cambodia), Yangon (Myanmar), and Lusaka (Zambia) to be separated from those who live in other urban areas within these countries, thus showing a heightened appreciation for contextual differences. Table 1 below shows the household sample sizes for the three countries selected for analysis, and Table 2 shows the cooking fuels commonly used by respondents in these areas. "Biomass" refers to firewood and/or charcoal. Although charcoal is the major fuel source for biomass cooking in urban Zambia, there is a more even split in the use of firewood and charcoal in urban Myanmar and urban Cambodia. The term "modern fuels" is preferred to "clean fuels", as LPG is a fossil fuel and electricity is generated from both renewable and non-renewable sources in all three countries. This definition is also consistent with the MTF reports themselves. Of the three case study contexts, LPG use is only prevalent in urban Cambodia.

Table 1. Number of surveyed households residing in urban areas, categorised by fuel types used for cooking.

\begin{tabular}{cccc}
\hline Country/Region & Biomass Only & $\begin{array}{c}\text { Biomass and Modern } \\
\text { Fuel(s) }\end{array}$ & $\begin{array}{c}\text { Modern Fuel(s) } \\
\text { Only }\end{array}$ \\
\hline Cambodia (all) & 241 & 736 & 668 \\
Phnom Penh & 23 & 370 & 543 \\
Rest of urban Cambodia & 191 & 366 & 125 \\
Myanmar (all) & 656 & 452 & 531 \\
Yangon & 42 & 127 & 190 \\
Rest of urban Myanmar & 614 & 325 & 341 \\
Zambia (all) & 1207 & 288 & 188 \\
Lusaka & 406 & 137 & 88 \\
Rest of urban Zambia & 801 & 151 & 100 \\
\hline
\end{tabular}

Table 2. Number of surveyed households residing in urban areas, categorised by cooking fuels.

\begin{tabular}{|c|c|c|c|c|c|c|c|}
\hline Urban Regions & $\begin{array}{c}\text { Biomass } \\
\text { Only }\end{array}$ & $\begin{array}{c}\text { Biomass } \\
\text { and } \text { LPG }^{1}\end{array}$ & $\begin{array}{l}\text { Biomass and } \\
\text { Electricity }\end{array}$ & $\begin{array}{l}\text { Biomass, } \\
\text { Electricity, } \\
\text { and LPG }\end{array}$ & $\begin{array}{l}\text { LPG } \\
\text { Only }\end{array}$ & $\begin{array}{c}\text { Electricity } \\
\text { Only }\end{array}$ & $\begin{array}{c}\text { Electricity } \\
\text { and LPG }\end{array}$ \\
\hline Phnom Penh & 23 & 117 & 16 & 237 & - & - & 360 \\
\hline Rest of urban Cambodia & 191 & 219 & 26 & 121 & - & - & 49 \\
\hline Yangon & 42 & 1 & 126 & - & 5 & 142 & 43 \\
\hline Rest of urban Myanmar & 614 & 11 & 314 & - & 18 & 252 & 71 \\
\hline Lusaka & 406 & - & 136 & - & 3 & 83 & - \\
\hline Rest of urban Zambia & 801 & - & 149 & - & 2 & 98 & - \\
\hline
\end{tabular}

${ }^{1}$ Columns 2-4 are equivalent to column 2 in Table 1 ('Stacking'); columns 5-7 are equivalent to column 3 in Table 1 ('Modern fuels only').

The content of the MTF surveys vary across different national contexts. The surveys used in Cambodia, Myanmar, and Zambia were comprehensive relative to many other country case studies included in the initiative, and data analysis has been performed on sections of the survey that are consistent across all three country case studies. It is acknowledged that the MTF survey data only presents a snapshot of energy access and cooking practices at one point in time (specifically, between May 2017 and March 2018), and that no questions were asked about the motivations that lie behind the choice to stack biomass and modern fuels for cooking. In the analysis that follows, it is impossible to infer causality concerning fuel-stacking practices. However, by comparing characteristics and practices across different national and urban contexts, it is possible to understand how different living situations are associated with the choice to stack fuels for cooking.

Measuring exactly how many fuels and technologies are being used involves considering the number of technologies in use, for how long they are used every day, and the variation of these factors over time. Understanding how stacking works and measuring 
stove use is vital to evaluating the adoption of a new technology or fuel. Due to stacking, the adoption of a new technology/fuel is not a black and white issue, and it is important to measure the extent to which a technology/fuel has been adopted [26]. To address this in relation to the MTF survey data, stacking households are divided based on how their expenditure on biomass compares to their expenditure on modern energy, with boundaries in relative spend creating three approximately equal stacking groups for each country (Table 3). Although these expenditures are not limited to cooking (i.e., biomass may also be used for space heating, electricity can be used for lighting, heating, entertainment), these divisions provide a sense of how dependent a fuel-stacking household is on biomass. Table 4 below shows the household sample sizes for these two separate categories for analysis. Households who do not provide expenditure data have been omitted, and therefore these sample sizes are smaller than the original number of stacking households in Table 1.

Table 3. Proportion of monthly fuel expenditure dedicated to biomass (not just for cooking).

\begin{tabular}{cccc}
\hline Country & $\begin{array}{c}\text { Biomass- } \\
\text { Intensive Stacking }\end{array}$ & $\begin{array}{c}\text { Mid-Range } \\
\text { Stacking }\end{array}$ & $\begin{array}{c}\text { Modern Fuel- } \\
\text { Intensive Stacking }\end{array}$ \\
\hline Cambodia & $>24 \%$ & $9-24 \%$ & $<9 \%$ \\
Myanmar & $>50 \%$ & $23-50 \%$ & $<23 \%$ \\
Zambia & $>37.5 \%$ & $23.5-37.5 \%$ & $<23.5 \%$ \\
\hline
\end{tabular}

Table 4. Number of surveyed households residing in urban areas, categorised by cooking fuels and the proportion of household spend on these fuels.

\begin{tabular}{|c|c|c|c|c|c|}
\hline Urban Regions & $\begin{array}{l}\text { Biomass } \\
\text { Exclusive }\end{array}$ & $\begin{array}{c}\text { Biomass- } \\
\text { Intensive } \\
\text { Stacking }\end{array}$ & $\begin{array}{c}\text { Mid-Range } \\
\text { Stacking }\end{array}$ & $\begin{array}{l}\text { Modern Fuel- } \\
\text { Intensive } \\
\text { Stacking }\end{array}$ & $\begin{array}{c}\text { Modern Fuel } \\
\text { Exclusive }\end{array}$ \\
\hline Phnom Penh & 23 & 69 & 88 & 113 & 543 \\
\hline Rest of urban Cambodia & 191 & 108 & 81 & 76 & 125 \\
\hline Yangon & 42 & 37 & 34 & 48 & 190 \\
\hline Rest of urban Myanmar & 614 & 108 & 108 & 74 & 341 \\
\hline Lusaka & 406 & 55 & 41 & 40 & 88 \\
\hline Rest of urban Zambia & 801 & 40 & 50 & 61 & 100 \\
\hline
\end{tabular}

The following section presents the findings of this analysis according to three themes: (a) household finances; (b) household dynamics; and (c) experiences of electricity and attitudes towards modern fuels. These three themes reflect the ongoing debates on fuel stacking within the literature.

\section{Results}

\subsection{Household Finances}

The energy ladder model assumes that higher income households will tend towards the use of clean-cooking fuels, as opposed to polluting alternatives, due to an increased capacity and willingness to pay for more expensive, more 'modern' fuels and appliances. Table 5 shows the mean and median monthly incomes of urban households residing in the three countries of study, grouped according to their fuel-stacking practices. 
Table 5. Average monthly household incomes in local currency (mean (median)).

\begin{tabular}{|c|c|c|c|c|c|c|}
\hline Urban Regions & $\begin{array}{l}\text { Biomass } \\
\text { Exclusive }\end{array}$ & $\begin{array}{l}\text { Biomass- } \\
\text { Intensive }\end{array}$ & $\begin{array}{c}\text { Mid-Range } \\
\text { Stacking }\end{array}$ & $\begin{array}{l}\text { Modern Fuel- } \\
\text { Intensive }\end{array}$ & $\begin{array}{l}\text { Modern Fuel } \\
\text { Exclusive }\end{array}$ & $\begin{array}{c}\text { Kruskal- } \\
\text { Wallis Test }\end{array}$ \\
\hline \multicolumn{7}{|l|}{ Cambodia $\left(100,000 \mathrm{KHR}^{1}\right)$} \\
\hline Phnom Penh & $15.9(12.0)$ & $32.6(23.0)$ & $36.3(20.0)$ & $40.3(30.0)$ & $30.5(20.0)$ & $<0.001$ \\
\hline Rest of urban Cambodia & $13.7(8.0)$ & $31.4(14.0)$ & $24.9 .9(13.4)$ & $26.9(20.0)$ & $29.5(15.0)$ & $<0.001$ \\
\hline \multicolumn{7}{|l|}{ Myanmar (10,000 MMK $\left.^{2}\right)$} \\
\hline Yangon & $14.8(15.0)$ & $22.8(15.0)$ & $14.3(15.0)$ & $20.5(12.5)$ & $22.6(17.0)$ & 0.376 \\
\hline Rest of urban Myanmar & $18.8(12.8)$ & $19.3(15.4)$ & $30.4(15.0)$ & $21.0(14.8)$ & $25.3(20.0)$ & $<0.001$ \\
\hline \multicolumn{7}{|l|}{ Zambia $\left(1000 \mathrm{ZMW}^{3}\right)$} \\
\hline Lusaka & $2.4(1.4)$ & $3.8(2.8)$ & $5.6(5.0)$ & $9.1(5.3)$ & $5.1(2.8)$ & $<0.001$ \\
\hline Rest of urban Zambia & $2.6(1.4)$ & $3.8(2.8)$ & $4.0(4.2)$ & $5.9(5.0)$ & $5.1(2.8)$ & $<0.001$ \\
\hline
\end{tabular}

${ }^{1} \mathrm{KHR}=$ Cambodian Riel; ${ }^{2} \mathrm{MMK}=$ Myanmar Kyat; ${ }^{3} \mathrm{ZMW}=$ Zambian Kwacha.

In Myanmar, household income is not a statistically significant factor in explaining differences across the different cooking fuel categories in Yangon (Table 5). In the rest of urban Myanmar, median incomes across the three stacking categories are all in the range of 148,000-153,500 kyat/month, while the median income of exclusive modern fuel households is significantly higher (200,000 kyat/month). Mean incomes tell a similar narrative in the rest of urban Myanmar, where statistical significance between the fuel categories can be established. Even though the rest of urban Myanmar includes households with connections to higher-tariff systems including mini-grids and border grids, these households do not change the income narrative. Although grid electricity is an inexpensive cooking fuel in Myanmar, a full transition to electric cooking appears to be favoured by higher income households, suggesting that other factors are important in eliminating fuel stacking such as access to reliable electricity or household preferences and tastes for 'modern' technologies.

In the Cambodian and Zambian contexts, higher household incomes are more strongly associated with fuel stacking than exclusive modern fuel cooking. In Lusaka, mean and median incomes increase incrementally from exclusive biomass households to modern fuelintensive households. Exclusive modern fuel households have lower mean and median incomes than two of the three stacking categories. Modern fuel-intensive households have the highest average incomes in the rest of urban Zambia also, while in Cambodia the differences between the stacking and exclusive modern fuel categories appear to be more mixed. In the rest of urban Cambodia, the highest mean income group is the biomass-intensive stackers, while the highest median group are modern fuel-intensive stackers. These results are shown in Table 5 below, but the variability and high average incomes among stackers challenge the narrative that rising incomes in sub-Saharan Africa, Southeast Asia and elsewhere will ensure clean cooking is adopted for $100 \%$ of household cooking needs.

Table 6 provides further detail into the relationship between household income and fuel-stacking practices, focusing on income per capita in each of the case study contexts.

When we analyse household income on a per capita basis, statistical significance is observed in all six geographical contexts. In Myanmar, there is a clear and distinct increase in average income/capita for modern fuel exclusive households, but for stacking households in Yangon, average income/capita falls as the proportional spend on electricity increases. In Phnom Penh and Lusaka, the average income/capita increases as the proportion of fuel spend on modern fuels increases, but the average is lower for the modern fuel exclusive use, once again challenging the energy ladder narrative that rising incomes will lead to the full adoption of clean cooking in the two regions. 
Table 6. Average monthly household incomes per capita in local currency (mean (median)).

\begin{tabular}{|c|c|c|c|c|c|c|}
\hline Urban Regions & $\begin{array}{l}\text { Biomass } \\
\text { Exclusive }\end{array}$ & $\begin{array}{l}\text { Biomass- } \\
\text { Intensive }\end{array}$ & $\begin{array}{c}\text { Mid-Range } \\
\text { Stacking }\end{array}$ & $\begin{array}{l}\text { Modern Fuel- } \\
\text { Intensive }\end{array}$ & $\begin{array}{c}\text { Modern Fuel } \\
\text { Exclusive }\end{array}$ & $\begin{array}{c}\text { Kruskal- } \\
\text { Wallis Test }\end{array}$ \\
\hline \multicolumn{7}{|l|}{ Cambodia (1000 KHR) } \\
\hline Phnom Penh & $508(257)$ & $703(460)$ & $824(450)$ & $896(567)$ & 797 (592) & $<0.001$ \\
\hline Rest of urban Cambodia & $297(200)$ & $696(300)$ & $562(306)$ & $567(394)$ & $813(400)$ & $<0.001$ \\
\hline \multicolumn{7}{|l|}{ Myanmar (1000 MMK) } \\
\hline Yangon & $37.4(35.7)$ & $47.1(41.7)$ & $33.7(27.5)$ & $42.0(18.4)$ & $65.1(45.0)$ & 0.041 \\
\hline $\begin{array}{l}\text { Rest of urban Myanmar } \\
\text { Zambia (ZMW) }\end{array}$ & $46.4(25.0)$ & $49.9(34.2)$ & $74.2(37.5)$ & $44.6(23.4)$ & $73.0(51.3)$ & $<0.001$ \\
\hline Lusaka & $583(319)$ & $824(516)$ & $1213(916)$ & $1743(1050)$ & 1507 (975) & $<0.001$ \\
\hline Rest of urban Zambia & $674(356)$ & $819(343)$ & $732(625)$ & $1368(1250)$ & $1586(833)$ & $<0.001$ \\
\hline
\end{tabular}

Table 7 shows the mean monthly fuel expenditures for households in each of the case study contexts. Due to data limitations, cooking cannot be separated from other uses of these fuels (lighting, heating, etc.), but overall fuel expenditures nevertheless provide an indication of the financial implications of fuel stacking for cooking.

Table 7. Mean monthly fuel expenditures (local currencies: KHR, MMK, ZMW).

\begin{tabular}{|c|c|c|c|c|c|}
\hline Urban Regions & Fuel $^{1}$ & $\begin{array}{l}\text { Biomass- } \\
\text { Intensive }\end{array}$ & $\begin{array}{l}\text { Mid-Range } \\
\text { Stack }\end{array}$ & $\begin{array}{l}\text { Modern Fuel- } \\
\text { Intensive }\end{array}$ & $\begin{array}{l}\text { Modern Fuel } \\
\text { Exclusive }\end{array}$ \\
\hline \multirow{4}{*}{$\begin{array}{l}\text { Phnom Penh } \\
\quad(K H R)\end{array}$} & Charcoal & 98,587 & 28,961 & 11,976 & - \\
\hline & Electricity & 88,014 & 129,547 & 231,914 & 129,441 \\
\hline & LPG & 29,956 & 29,572 & 38,498 & 31,092 \\
\hline & Total & 216,557 & 188,080 & 282,388 & 163,818 \\
\hline \multirow{4}{*}{$\begin{array}{l}\text { Rest of urban Cambodia } \\
\qquad(K H R)\end{array}$} & Charcoal & 67,251 & 17,775 & 8930 & - \\
\hline & Electricity & 45,045 & 74,297 & 173,948 & 74,880 \\
\hline & LPG & 19,451 & 26,172 & 30,002 & 28,566 \\
\hline & Total & 130,690 & 118,243 & 212,879 & 121,144 \\
\hline \multirow{3}{*}{$\begin{array}{l}\text { Yangon } \\
(M M K)\end{array}$} & Charcoal & 17,727 & 3139 & 1580 & 79 \\
\hline & Electricity & 3620 & 6003 & 12,702 & 8650 \\
\hline & Total & 21,347 & 9142 & 14,418 & 10,110 \\
\hline \multirow{3}{*}{$\begin{array}{l}\text { Rest of urban Myanmar } \\
\qquad(M M K)\end{array}$} & Charcoal & 21,910 & 6088 & 3225 & 189 \\
\hline & Electricity & 5437 & 12,041 & 24,931 & 13,534 \\
\hline & Total & 27,648 & 18,128 & 29,376 & 16,631 \\
\hline Lusaka & Charcoal & 137 & 88 & 62 & 2 \\
\hline \multirow[t]{2}{*}{$(\mathrm{ZMW})$} & Electricity & 139 & 205 & 286 & 180 \\
\hline & Total & 273 & 293 & 354 & 206 \\
\hline \multirow{3}{*}{$\begin{array}{l}\text { Rest of urban Zambia } \\
(Z M W)\end{array}$} & Charcoal & 129 & 79 & 59 & 2 \\
\hline & Electricity & 145 & 184 & 305 & 159 \\
\hline & Total & 274 & 263 & 371 & 174 \\
\hline
\end{tabular}

${ }^{1}$ Kruskal-Wallis Test based on mean fuel expenditures $<0.001$ for all fuels in each geographical context.

The data shows that households belonging to specific fuel-stacking categories have higher expenditures than exclusive modern fuel households on both a total and per capita basis. In Yangon, where grid electricity is relatively inexpensive, fuel expenditures are highest among biomass-intensive households, reaffirming the notion that non-financial barriers to transition exist. In both Cambodia and Zambia, modern fuel-intensive households spend the most on a total and per capita basis. Table 7 shows that in Phnom Penh and the rest of urban Cambodia the transition towards modern fuel appears to be driven by an increase in electricity consumption as opposed to LPG consumption. The amount of biomass spend in the Cambodian urban contexts significantly reduces along the fuel-stacking categories, and 
to a much greater extent than in Zambian urban contexts. In contrast, stackers in Lusaka and the rest of urban Zambia remain more reliant on biomass.

Fuel is only one aspect of regular household expenditure. The MTF data also asks households how much money they spend in a month on food and drink, medical expenses, water, mobile phones, internet, rent and transport. Food/drink expenditure data are collected on a weekly basis, and this has been multiplied by 4 to estimate monthly expenditure. Other yearly expenditure figures collected from participants (e.g., schooling) are omitted, and thus the figures presented here are not a complete representation of total household expenditures. Figure 2 below shows the proportional expenditures for the three combined fuel-stacking categories for each of the six geographical contexts.

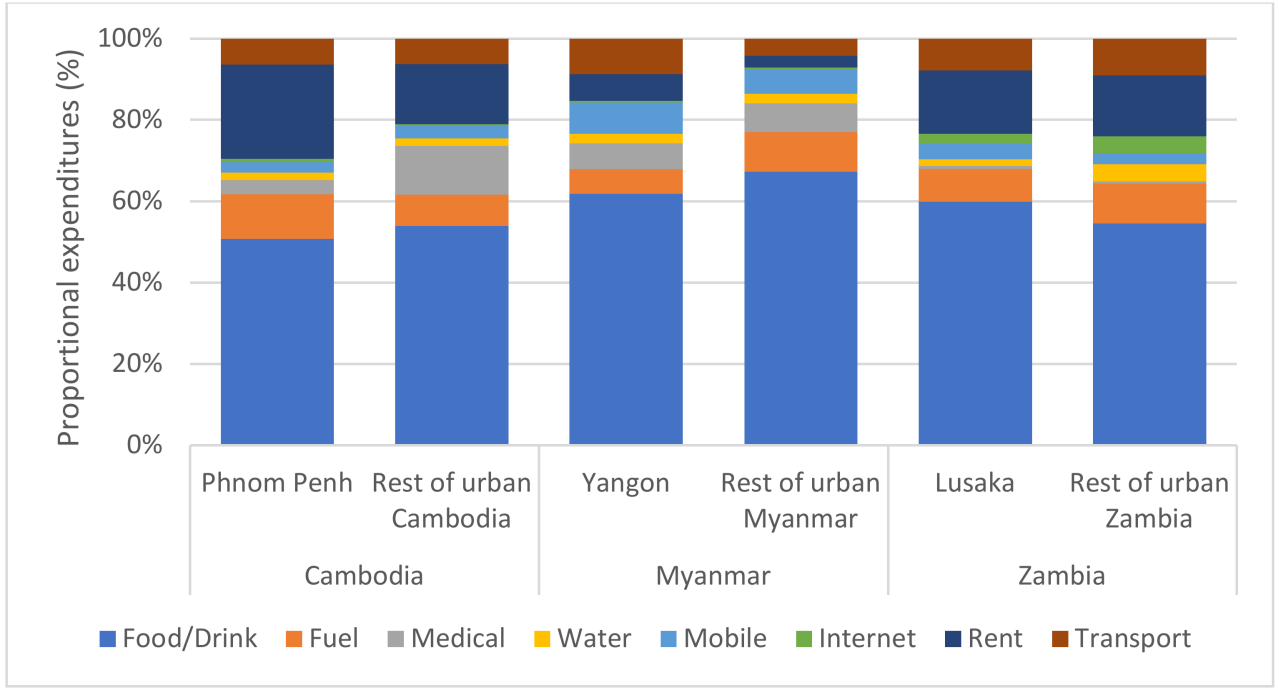

Figure 2. Proportional monthly expenditures for households stacking biomass with modern fuels for cooking.

In each of the geographical contexts under study, food and drink is the highest proportion of average spend relative to the other categories, accounting for $47-74 \%$ of total specified expenditures. In Cambodia and Zambia, the next highest expenditures are rent $(8-28 \%)$ and fuel (6-12\%). In Myanmar, fuel (4-13\%), medical expenses (3-14\%) and mobile phones (5-9\%) are the next highest categories after food and drink.

As with fuel expenditures, modern fuel-intensive stackers tend to spend more on these categories overall than exclusive modern fuel households, although in Yangon there is little difference across the three stacking categories. Table 8 below shows which of the categories are statistically significant in explaining differences between biomass-intensive and modern fuel-intensive households. Table 9 shows the significant differences between modern fuel-intensive and exclusive modern fuel households.

In urban Cambodia (and Phnom Penh in particular), modern fuel-intensive stacking is associated with high consumption levels across the different categories, when compared to other stackers as well as with exclusive modern fuel households. The same is true in urban Zambia, but these associations are more limited to fuel, water and mobile/internet expenses. In Myanmar, stackers as a whole tend to spend more than exclusive modern fuel households on food and drink, fuel, and water, but less on rent. Supported by the review of qualitative research into fuel-stacking practices in Section 2 of this paper, these findings suggest that the clean-cooking sector needs to widen its focus from the costs of fuels to the wider range of expenses that come with urbanised living. 
Table 8. Monthly expenditure items with a statistically significance difference between biomass-intensive and modern fuel-intensive households ( $X=$ significant,$+/-=$ increase/decrease in expenditure).

\begin{tabular}{|c|c|c|c|c|c|c|c|c|}
\hline Urban Regions & Food/Drink & Fuel & Medical & Water & Mobile & Internet & Rent & Transport \\
\hline Phnom Penh & $X(+)$ & $X(+)$ & & $X(+)$ & $X(+)$ & $X(+)$ & & \\
\hline $\begin{array}{c}\text { Rest of urban Cambodia } \\
\text { Yangon }\end{array}$ & $X(+)$ & $X(+)$ & & $X(+)$ & $X(-)$ & & & \\
\hline Rest of urban Myanmar & & & & $X(+)$ & & & & \\
\hline Lusaka & & $X(+)$ & & & & & & \\
\hline Rest of urban Zambia & & $X(+)$ & & $X(+)$ & & $X(+)$ & & \\
\hline
\end{tabular}

Table 9. Monthly expenditure items with a statistically significance difference between modern fuel-intensive and modern fuel exclusive households ( $\mathrm{X}=$ significant,$+/-=$ increase/decrease in expenditure).

\begin{tabular}{|c|c|c|c|c|c|c|c|c|}
\hline Urban Regions & Food/Drink & Fuel & Medical & Water & Mobile & Internet & Rent & Transport \\
\hline Phnom Penh & $X(-)$ & $X(-)$ & $X(-)$ & $X(-)$ & $X(-)$ & $X(-)$ & & $X(+)$ \\
\hline Rest of urban Cambodia & $X(-)$ & $X(-)$ & & & $X(-)$ & & & $X(-)$ \\
\hline Yangon & $X(-)$ & $X(-)$ & & & & & $X(+)$ & \\
\hline Rest of urban Myanmar & & $X(-)$ & & $X(-)$ & & & & \\
\hline Lusaka & $X(-)$ & $X(-)$ & & & & & & \\
\hline Rest of urban Zambia & & $X(-)$ & & $X(-)$ & & $X(-)$ & & \\
\hline
\end{tabular}

\subsection{Household Dynamics}

Table 10 shows the mean household size of households in the six case study contexts, categorized according to their fuel-stacking practices.

Table 10. Mean household size.

\begin{tabular}{ccccccc}
\hline Urban Regions & $\begin{array}{c}\text { Biomass } \\
\text { Exclusive }\end{array}$ & $\begin{array}{c}\text { Biomass- } \\
\text { Intensive }\end{array}$ & $\begin{array}{c}\text { Mid-Range } \\
\text { Stacking }\end{array}$ & $\begin{array}{c}\text { Modern Fuel- } \\
\text { Intensive }\end{array}$ & $\begin{array}{c}\text { Modern Fuel } \\
\text { Exclusive }\end{array}$ & $\begin{array}{c}\text { Kruskal- } \\
\text { Wallis Test }\end{array}$ \\
\hline Phnom Penh & 4.17 & 5.00 & 4.88 & 5.16 & 4.21 & $<0.001$ \\
Rest of urban Cambodia & 4.95 & 4.84 & 4.96 & 5.11 & 4.10 & 0.006 \\
Yangon & 4.45 & 5.32 & 5.06 & 6.21 & 4.13 & $<0.001$ \\
Rest of urban Myanmar & 5.02 & 4.52 & 4.69 & 4.97 & 4.10 & $<0.001$ \\
Lusaka & 5.30 & 5.75 & 4.66 & 5.75 & 3.66 & $<0.001$ \\
Rest of urban Zambia & 5.19 & 6.18 & 6.20 & 4.89 & $<0.001$ \\
\hline
\end{tabular}

For all six geographical contexts, the household size of stackers is larger than exclusive modern fuel households, with statistical significance of 0.006 or lower (Kruskal-Wallis). The rest of urban Cambodia and the rest of urban Myanmar are the only contexts where the average household size of exclusive biomass households is larger than fuel-stacking households. Except for exclusive biomass households, which tend to be smaller in size in Phnom Penh (mean $=4.17$ ) compared to the rest of urban Cambodia (mean $=4.95)$, the two Cambodian contexts are very similar in average household size across the fuel stacking and exclusive modern fuel categories. In Myanmar, households in Yangon show greater variability than the rest of urban Myanmar, with noticeably larger household sizes for stackers (5.55, compared to 4.67 for all households). The opposite is true for Zambia; the major city has less variability than the average household size in the rest of the country. Furthermore, the data indicates that fuel stacking and a reliance on biomass are associated with larger households in the rest of urban Zambia.

The literature review above forwarded the argument that fuel stacking is related to a need to cook for more people, and hence the need for multiple stoves or devices. Larger household sizes also suggest an increased importance for contingency fuels due to the number of dependents within the household, while larger families may also present additional financial pressures not limited to the cost of fuel. Finally, a transition to modern fuels may go hand-in-hand with contemporary urban lifestyles, and the desire and ability 
for smaller, nuclear families. These findings appear to support this assertion, although there are significant differences across the three categories of households that stack biomass with modern fuels. There is insufficient data to explain these differences, or how larger households may be best positioned to reduce their use of biomass relative to modern fuels. This is yet another example of how local stakeholder engagement and qualitative research can provide much-needed nuance to these differences.

It is also important to explore how the ownership of electrical appliances varies with the extent to which households use modern energy for their cooking. For instance, if all households with an electricity connection own a specific appliance, regardless of whether they cook with electricity, biomass, or a combination, it would suggest that this appliance is not important in transitioning households away from polluting fuels. If, however, ownership rates increase significantly for those cooking mostly or exclusively with modern fuels, the appliance may be an indicator of the propensity to transition, or might even play a role itself in reducing the need for biomass for cooking.

Table 11 shows electrical appliance ownership rates for different categories of households. Due to data limitations, the table includes households in the major cities only, and focuses only on the three secondary electric kitchen appliances that are relatively common across all three contexts. These appliances are rice cookers, kettles, and refrigerators.

Table 11. Appliance ownership rate (households that did not complete this section of the survey are omitted).

\begin{tabular}{|c|c|c|c|c|c|c|}
\hline Urban Regions & Appliance & $\begin{array}{l}\text { Biomass- } \\
\text { Intensive }\end{array}$ & $\begin{array}{l}\text { Mid-Range } \\
\text { Stacking }\end{array}$ & $\begin{array}{l}\text { Modern Fuel- } \\
\text { Intensive }\end{array}$ & $\begin{array}{c}\text { Modern Fuel } \\
\text { Exclusive }\end{array}$ & $\begin{array}{c}\text { Chi-Squared } \\
\text { Test }\end{array}$ \\
\hline \multirow[t]{3}{*}{ Phnom Penh } & Rice Cooker & $64 \%$ & $61 \%$ & $80 \%$ & $67 \%$ & 0.710 \\
\hline & Kettle & $14 \%$ & $15 \%$ & $20 \%$ & $17 \%$ & 0.968 \\
\hline & Refrigerator & $32 \%$ & $44 \%$ & $61 \%$ & $40 \%$ & 0.017 \\
\hline \multirow[t]{3}{*}{ Yangon } & Rice Cooker & $89 \%$ & $91 \%$ & $98 \%$ & $96 \%$ & 0.147 \\
\hline & Kettle & $62 \%$ & $74 \%$ & $75 \%$ & $69 \%$ & 0.590 \\
\hline & Refrigerator & $43 \%$ & $47 \%$ & $71 \%$ & $64 \%$ & 0.015 \\
\hline \multirow[t]{3}{*}{ Lusaka } & Rice Cooker & $9 \%$ & $22 \%$ & $18 \%$ & $9 \%$ & 0.232 \\
\hline & Kettle & $33 \%$ & $32 \%$ & $40 \%$ & $27 \%$ & 0.995 \\
\hline & Refrigerator & $76 \%$ & $78 \%$ & $90 \%$ & $66 \%$ & 0.838 \\
\hline
\end{tabular}

In Yangon, the rate of ownership of all three appliances increases among fuel-stacking households as the proportion of modern fuel expenditure increases. However, the ownership rate falls among exclusive modern fuel households compared to modern fuel-intensive stackers. In fact, this finding applies across all six geographical contexts for all three appliances. In Zambia, urban households are more likely to own a fridge than either a kettle or rice cooker.

Rice cookers are owned almost universally in Myanmar among those cooking with modern fuels for at least some of their cooking needs. The prevalence of LPG in Cambodia explains lower ownership rates of rice cookers and kettles compared to Myanmar, but both appliances appear to be associated with a decline in use of biomass for cooking among stacking households. When it comes to testing for statistical significance (Chi-squared), the only rates of ownership that apply are fridges in Cambodia and Myanmar (the major cities as well as the other urban regions). This may be surprising given that fridges do not directly displace the need for a biomass stove, at least in terms of cooking food. Rather, fridges are perhaps a better indicator of reliable electricity, affordability, and/or a preference for modern appliances. Fridges also preserve food, and the review of the literature revealed this can be particularly important in the absence of smoke in some contexts [23].

\subsection{Experiences of Electricity}

It is also important to explore whether the quality of the electricity supply impacts a household's willingness to (a) use, and (b) depend on electricity for cooking and other domestic activities. Given the prevalence of LPG and a stable electricity supply in Phnom 
Penh, statistical significance was not achieved in differentiating between the different household fuel categories in the city, regarding the variability in electricity supply and the number of blackouts. Table 12 shows the percentage of households that reported no variability in the quality of electricity supply over a 12-month period.

Table 12. Percentage of households that stated the quality of their electricity supply remains constant over the course of a 12-month period.

\begin{tabular}{|c|c|c|c|c|c|c|}
\hline Urban Regions & $\begin{array}{l}\text { Biomass } \\
\text { Exclusive }\end{array}$ & $\begin{array}{l}\text { Biomass- } \\
\text { Intensive }\end{array}$ & $\begin{array}{c}\text { Mid-Range } \\
\text { Stacking }\end{array}$ & $\begin{array}{l}\text { Modern Fuel- } \\
\text { Intensive }\end{array}$ & $\begin{array}{l}\text { Modern Fuel } \\
\text { Exclusive }\end{array}$ & $\begin{array}{c}\text { Chi-Squared } \\
\text { Test }\end{array}$ \\
\hline Phnom Penh & $90 \%$ & $98 \%$ & $96 \%$ & $99 \%$ & $98 \%$ & 0.157 \\
\hline Rest of urban Cambodia & $88 \%$ & $87 \%$ & $75 \%$ & $79 \%$ & $89 \%$ & 0.039 \\
\hline Yangon & $89 \%$ & $43 \%$ & $50 \%$ & $69 \%$ & $70 \%$ & $<0.001$ \\
\hline Rest of urban Myanmar & $77 \%$ & $72 \%$ & $61 \%$ & $58 \%$ & $81 \%$ & $<0.001$ \\
\hline Lusaka & $53 \%$ & $51 \%$ & $54 \%$ & $51 \%$ & $81 \%$ & $<0.001$ \\
\hline Rest of urban Zambia & $63 \%$ & $78 \%$ & $70 \%$ & $77 \%$ & $85 \%$ & $<0.001$ \\
\hline
\end{tabular}

In general, a lower proportion of households in the fuel-stacking categories report no variability in the electricity supply compared to those that have made the full transition to modern fuels. The fuel-stacking categories themselves show no clear pattern, which in the rest of urban Cambodia may be related to the presence of LPG as a modern fuel alternative to electricity. This may also be explained by the fact that biomass-orientated households may limit their use of electricity (e.g., lighting, a little cooking), and variability in supply may have less of an impact. Variability in Lusaka and Yangon are much lower for fuel-stacking categories compared to other urban households in Zambia and Myanmar, respectively. The opposite is true in Cambodia, where variability is reported by $4.1 \%$ or less among the categories of households that cook with modern fuels partially or exclusively.

Table 13 shows the average number of blackouts households experience in a typical week in the rest of urban Myanmar and the rest of urban Zambia: the two contexts where blackouts were relatively common. Although respondents were also asked about the number of blackouts in the worst week of the year, the number of responses to this question are too small to include in the analysis.

Table 13. Average number of blackouts experienced by households in a typical week ( $n=$ number of respondents).

\begin{tabular}{|c|c|c|c|c|c|c|}
\hline Urban Regions & & $\begin{array}{l}\text { Biomass- } \\
\text { Intensive }\end{array}$ & $\begin{array}{l}\text { Mid-Range } \\
\text { Stacking }\end{array}$ & $\begin{array}{l}\text { Modern Fuel- } \\
\text { Intensive }\end{array}$ & $\begin{array}{l}\text { Modern Fuel } \\
\text { Exclusive }\end{array}$ & $\begin{array}{c}\text { Kruskal- } \\
\text { Wallis Test }\end{array}$ \\
\hline \multirow[b]{2}{*}{ Rest of urban Myanmar } & $n$ & 82 & 74 & 54 & 264 & \multirow[b]{2}{*}{0.002} \\
\hline & $\begin{array}{l}\text { Blackouts } \\
\text { / week }\end{array}$ & 3.78 & 3.31 & 1.54 & 2.92 & \\
\hline \multirow[b]{2}{*}{ Rest of urban Zambia } & n & 33 & 46 & 54 & 92 & \multirow[b]{2}{*}{0.007} \\
\hline & $\begin{array}{l}\text { Blackouts } \\
\text { /week }\end{array}$ & 1.09 & 0.87 & 1.04 & 0.8 & \\
\hline
\end{tabular}

For blackouts in a typical week, statistical significance between the household fuel categories is established only in the rest of urban Myanmar (Kruskal-Wallis =0.002) and the rest of urban Zambia (0.007). In the Zambian contexts, households tend to experience roughly one blackout in a typical week, and this reduces slightly for exclusive modern fuel households. In the rest of urban Myanmar, however, there is a significant difference between modern fuel-intensive stackers and the three other electric cooking categories. This suggests that a much-improved electricity supply is not enough to facilitate a full transition to exclusive modern energy cooking in these contexts. Further analysis suggests that the rest of urban Myanmar varies significantly in terms of the issue of blackouts, although small sample sizes limit the strength of this analysis. In Mandalay, fuel-stacking households report a mean of 10.03 blackouts in a typical week $(n=34$, median $=5)$, while in urban areas of Shan State, this figure is just 1.75 blackouts/week $(n=57$, median $=1)$. 
The three country-specific surveys all ask respondents to list the two main challenges they face regarding their electricity supply. Due to small sample sizes, the three fuelstacking categories have been combined and then compared with exclusive modern fuel households. Figures $3-5$ below present the proportion of responses for the six geographical contexts. Responses of 'no problems' have only been included if the household had not already identified one problem as their first answer.

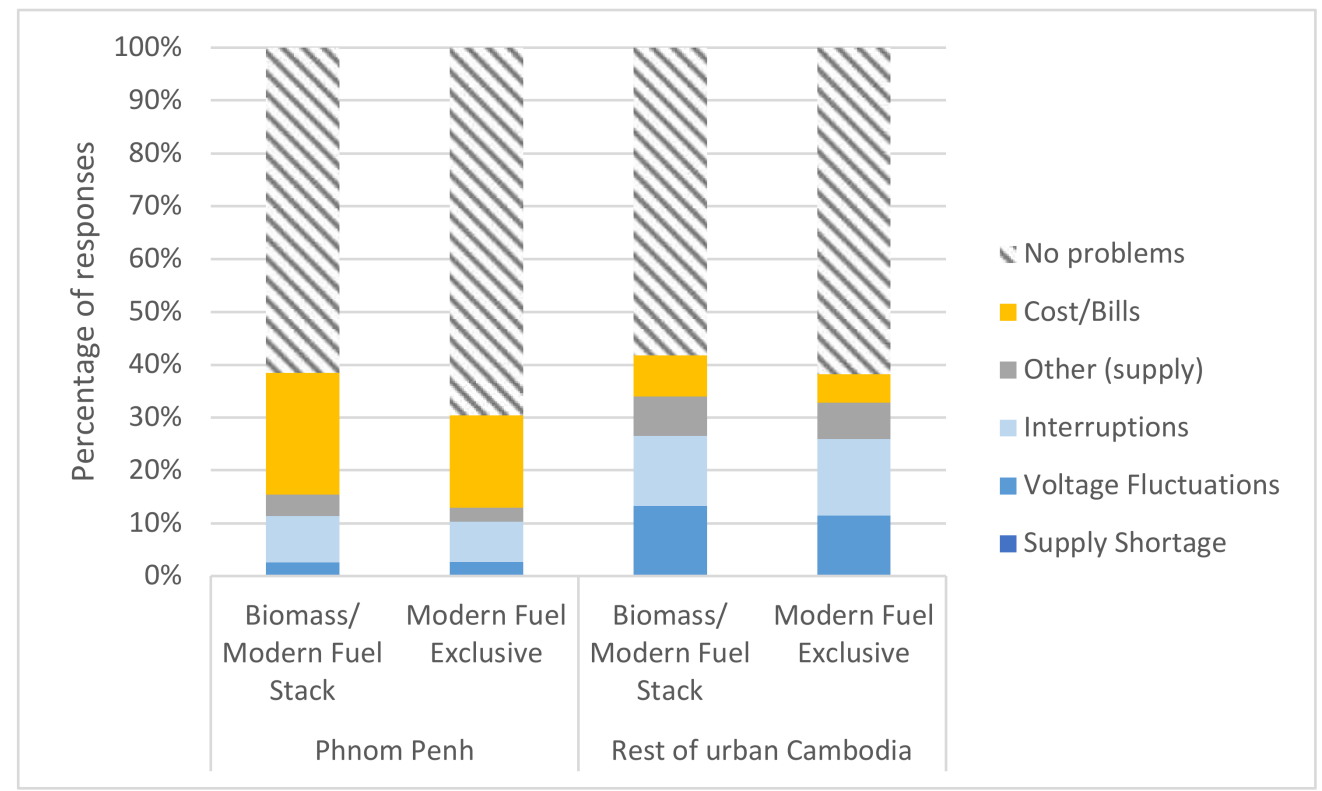

Figure 3. The main problems with a household's electricity supply, Cambodia (up to two responses per household).

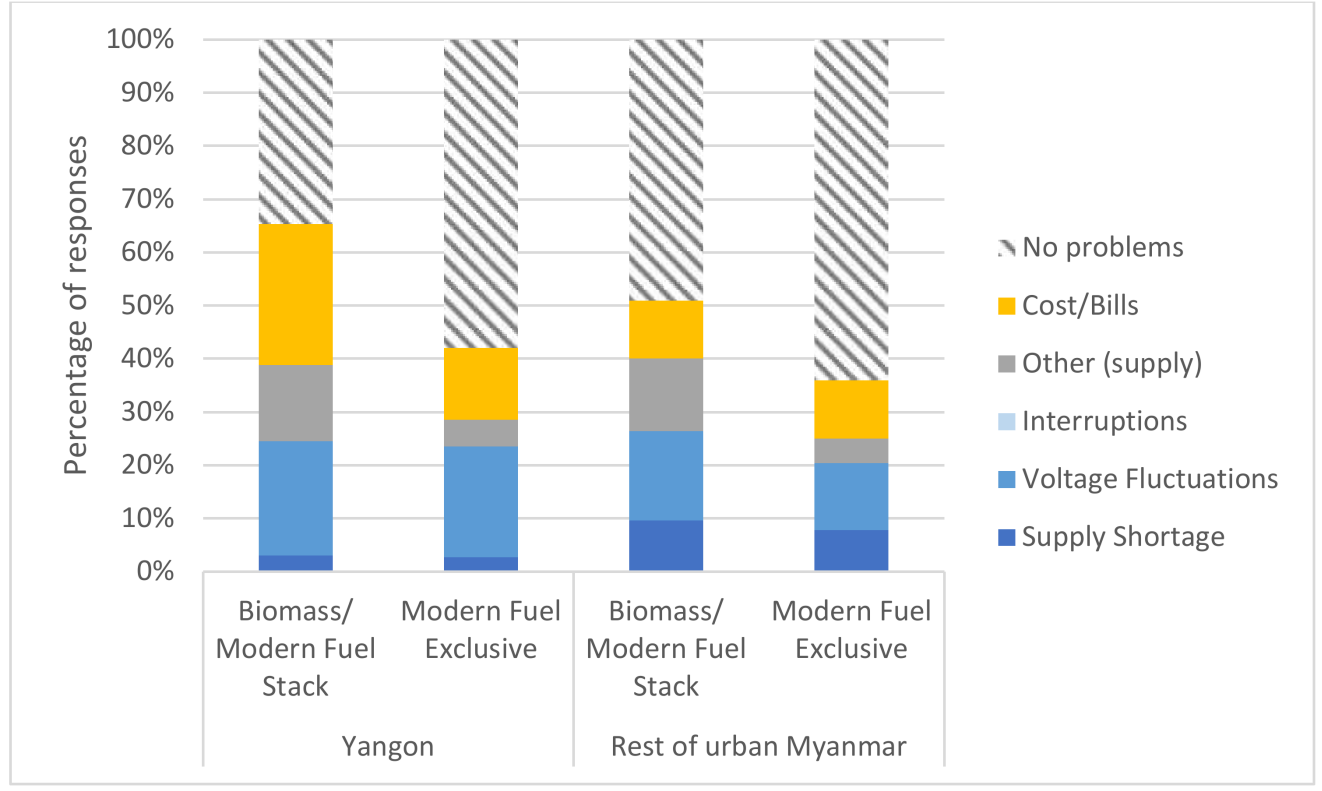

Figure 4. The main problems with a household's electricity supply, Myanmar (up to two responses per household). 


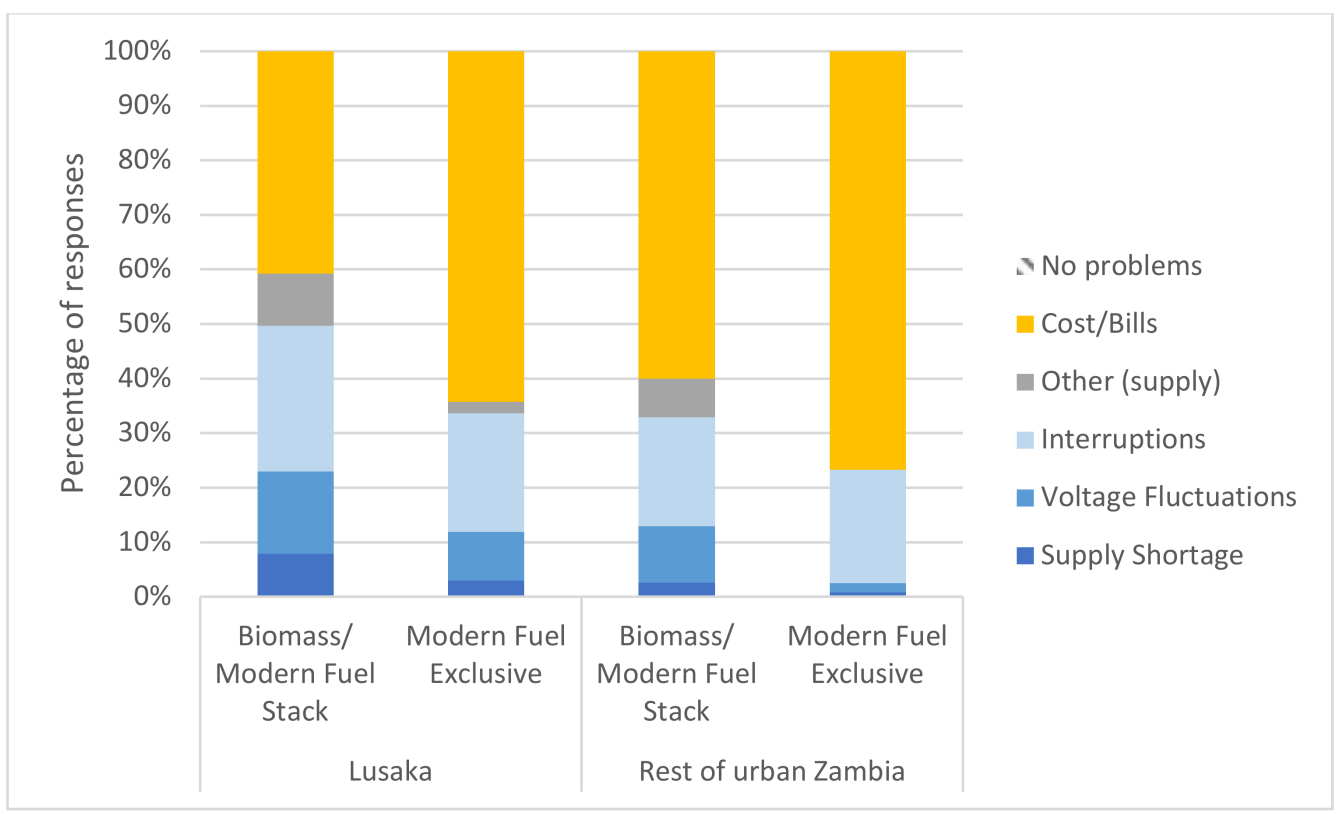

Figure 5. The main problems with a household's electricity supply, Zambia (up to two responses per household).

The MTF survey in Zambia was either administered differently than the other two, or all responding households identified a problem related to either the quality of supply or the cost of the service. The data suggests that electricity challenges are more concentrated among fuel stackers than those that have fully transitioned to modern energy. Challenges related to the quality of supply are much lower in Phnom Penh than the rest of urban Cambodia, but the same cannot be said in the major cities in Myanmar or Zambia. Interruptions are the major supply issue in urban Zambia, whereas in Myanmar the major concern is voltage fluctuations. In Cambodia, the major concern is split between interruptions and supply shortage (hours of availability). Consumer financing and pre-payment solutions may play a significant role in enabling many fuel-stacking households to fully transition to modern energy cooking.

Finally, the Cambodia and Myanmar surveys ask attitudinal questions of the households relating to cooking fuels. Given that LPG is widely used in urban Cambodia, but not in Myanmar, households have been categorised according to the individual fuels they use-either exclusive or stacked with others. Although the attitudes stated differences across the two surveys, three questions specific to cooking fuels were present in both, and the results are presented below in Table 14 .

Table 14. Mean responses to attitudinal questions relating to biomass and modern fuels $(1=$ agree; $-1=$ disagree).

\begin{tabular}{|c|c|c|c|c|c|c|c|}
\hline Urban Regions & $\begin{array}{c}\text { Biomass } \\
\text { Only }\end{array}$ & $\begin{array}{c}\text { Biomass } \\
\text { and } \mathrm{LPG}^{2}\end{array}$ & $\begin{array}{l}\text { Biomass } \\
\text { and } \\
\text { Electricity }\end{array}$ & $\begin{array}{l}\text { Biomass, } \\
\text { Electricity, } \\
\text { and LPG }\end{array}$ & $\begin{array}{l}\text { LPG } \\
\text { Only }\end{array}$ & $\begin{array}{c}\text { Electricity } \\
\text { Only }\end{array}$ & $\begin{array}{c}\text { Electricity } \\
\text { and LPG }\end{array}$ \\
\hline \multicolumn{8}{|c|}{ Electricity is expensive for cooking ... 1} \\
\hline Phnom Penh & - & 0.61 & - & 0.55 & - & - & 0.46 \\
\hline Rest of urban Cambodia & - & 0.60 & - & 0.59 & - & - & - \\
\hline Yangon & - & - & -0.40 & - & - & -0.20 & - \\
\hline Rest of urban Myanmar & 0.36 & - & 0.10 & - & - & -0.37 & - \\
\hline \multicolumn{8}{|c|}{ LPG is expensive for cooking household meals ... ${ }^{2}$} \\
\hline Phnom Penh & - & 0.30 & - & 0.44 & - & - & 0.12 \\
\hline Rest of urban Cambodia & - & 032 & - & 0.33 & - & - & - \\
\hline Yangon & - & - & 0.40 & - & - & 0.57 & - \\
\hline Rest of urban Myanmar & 0.72 & - & 0.61 & - & - & 0.61 & 0.00 \\
\hline
\end{tabular}


Table 14. Cont.

\begin{tabular}{|c|c|c|c|c|c|c|c|}
\hline Urban Regions & $\begin{array}{c}\text { Biomass } \\
\text { Only }\end{array}$ & $\begin{array}{c}\text { Biomass } \\
\text { and } \mathrm{LPG}^{2}\end{array}$ & $\begin{array}{c}\text { Biomass } \\
\text { and } \\
\text { Electricity }\end{array}$ & $\begin{array}{l}\text { Biomass, } \\
\text { Electricity, } \\
\text { and LPG }\end{array}$ & $\begin{array}{l}\text { LPG } \\
\text { Only }\end{array}$ & $\begin{array}{c}\text { Electricity } \\
\text { Only }\end{array}$ & $\begin{array}{c}\text { Electricity } \\
\text { and LPG }\end{array}$ \\
\hline \multicolumn{8}{|c|}{ Certain food tastes better when cooked with biomass compared to gas or electricity ... ${ }^{3}$} \\
\hline Phnom Penh & - & 0.37 & - & 0.36 & - & - & -0.07 \\
\hline Rest of urban Cambodia & - & 0.30 & - & 0.38 & - & - & - \\
\hline Yangon & - & - & -0.15 & - & - & 0.01 & - \\
\hline Rest of urban Myanmar & -0.19 & - & 0.05 & - & - & 0.07 & - \\
\hline
\end{tabular}

${ }^{1}$ Statistical significance for the rest of urban Myanmar only (Mann-Whitney $<0.001$ across all three categories; ${ }^{2}$ Statistical significance for Phnom Penh only ('Biomass, Electricity, and LPG' to 'Electricity and LPG' households, Mann-Whitney < 0.001); ${ }^{3}$ Statistical significance for Phnom Penh (all three categories, Mann-Whitney < 0.001) and for the rest of urban Myanmar (Biomass exclusive to 'Biomass and Electricity' households, Mann-Whitney =0.013; 'Biomass Exclusive' to 'Electricity Only' $=0.017$ ).

Cambodian households tend to perceive electricity and LPG as expensive for cooking, and biomass-cooked food as better tasting, but the extent of this reduces for those that have fully transitioned to modern fuels. A preference for biomass-cooked food is much more prevalent in the rest of urban Cambodia compared to in the capital.

Electricity tends to be perceived as inexpensive in Yangon, but expensive in the rest of urban Myanmar. LPG is widely regarded as expensive for those not currently cooking with the fuel. Households in Myanmar tend to be indifferent about the taste of food cooked with biomass or modern fuels. In the rest of urban Myanmar, exclusive biomass households are less likely to prefer biomass-cooked food, suggesting a desire for transition. Across both countries, statistical significance could not be achieved in most cases, suggesting that there is no significant change in attitudes between households that vary their relative use of biomass and/or modern fuels for cooking. Combining these findings with the literature review, which showed a range of cultural influences influencing fuel choice and cooking practices, it is essential for future data collection activities to explore household perceptions and preferences in much more detail.

\section{Discussion}

The literature review showed there are several practical reasons for fuel stacking that do not necessarily pertain to fuel costs or health consequences. Fuel security concerns, cooking multiple dishes simultaneously and/or cooking for large numbers, and the familiarity of biomass stoves are some of the factors that explain why biomass continues to be used even when modern fuels are available for cooking. Furthermore, modern technologies can be perceived by some to change cooking practices and household gender dynamics, and while these shifts may be highly desirable for some households, the literature review shows that these shifts can also cause apprehension and unease. Even though modern fuels are becoming increasingly cost competitive in urban settings, these insights suggest that fuel stacking will remain a part of people's cooking practices in the future.

As a result, more research is needed to understand the factors associated with different fuel-stacking practices in specific contexts. The middle section of this paper addresses this research gap. Analysis of the World Bank's MTF data reveals that in urban Myanmar, it is non-financial barriers that appear to explain fuel-stacking practices the best, most notably household size and voltage fluctuations. In Cambodia, fuel consumption patterns are closely tied to consumption of other essential household items, and higher incomes and higher fuel expenditures appear to be associated with the minimisation (but not elimination) of biomass. A similar pattern is observed in urban Zambia, although it appears interruptions to the electricity supply are also an important factor that explains the relative use of charcoal and electricity for cooking. In the absence of attitudinal questions in the Zambia survey, and with only a limited number of questions relevant to fuel use in the Cambodia and Myanmar surveys, it is difficult to make substantive conclusions about how perceptions contribute to fuel-stacking practices. 
Furthermore, this analysis has shown significant variability in the ways in which the residents of the major cities of Cambodia, Myanmar, and Zambia relate to urban households living elsewhere in these respective countries. Phnom Penh households tend to face less constraints than those residing in the rest of urban Cambodia, but the same cannot be said for Lusaka and Yangon. In fact, the characteristics of fuel-stacking households in Yangon are in many ways more similar to households in Lusaka than their regional neighbours in Phnom Penh, thus throwing into question the generalisability of transitions of Southeast Asian countries as a collective regional entity. Small sample sizes in regional cities such as Siem Reap (Cambodia), Mandalay (Myanmar) and the Copperbelt (Zambia) have limited the prospect of capturing the nuances of fuel stacking in specific regions and locales [46]. Cities themselves are unequal places, and a greater understanding of local contexts is critical to accelerating clean-cooking transitions.

This analysis shows there is nothing inevitable about the role fuel stacking plays in the transition from exclusive biomass cooking to exclusive modern energy cooking. Fuel-stacking practices are complex and varied even within the same geographical context; some households with the means to transition to exclusive modern energy cooking choose to continue to include biomass in their cooking practices, while other, more financially constrained, households may use modern energy to meet their cooking needs as and when their situation allows.

One of the most important questions that arise from the data is how the clean-cooking sector should operate in contexts where the quality of electricity supply is poor and/or variable. One important conclusion is that significant numbers of households in these geographical contexts have transitioned to exclusive modern energy cooking while continuing to face challenges related to affordability and reliability. Although the literature suggests that many of these households may revert to the use of biomass for cooking, it also suggests a desire and willingness among many households to use modern energy when available. Fuel stacking, in this context, allows households to vary their practices according to how these constraints change over time. In Cambodia, LPG seems to play an important role in mitigating these constraints and allowing for exclusive modern energy cooking in a wider range of contexts. However, limiting the use of biomass among fuel-stacking households in Cambodia appears to be related to an uptick in electricity use, rather than LPG use.

The issue of variable electricity supply does not rule out electricity as a vital source of clean energy for cooking. Given that some households persist with electric cooking even when facing challenges related to affordability and the quality of supply, there is clearly a place for innovations in electric cooking to accelerate the transition, and particularly around increased efficiency, quick-cook and/or low-powered appliances, and battery-supported electric cooking. Furthermore, given the improved/increased range of electric cooking appliances now available, more research is needed to understand the apprehensions of biomass users and in turn match their cooking needs with the most appropriate appliances.

Finally, it is important to note that the complexities of fuel stacking will likely have been compounded by the COVID-19 pandemic and, in the case of Myanmar, the crisis that has followed the military coup in February 2021. Urban populations across the world have faced difficulties accessing cash, fuel, and basic food items (e.g., [47]) and, even within the same contexts, the panic buying of cooking fuels has been observed alongside a large-scale reversion back to the use of biomass for cooking [48]. In Myanmar, disruption to the country's electricity supply is seen as a key battleground in the fight to end junta rule [49]. These crises remind us that fuel stacking is a complex set of practices that cannot be removed from political, economic, and cultural contexts. Crisis situations, policy changes, illegal biomass markets, and other external influences can limit and even reverse existing transition pathways for clean cooking. The future of fuel stacking and its potential role in clean-cooking transitions will remain uncertain over the next few years, and this only strengthens the need for the clean-cooking sector to engage local stakeholders and communities to assess the viability of different transition pathways available to them. 


\section{Conclusions}

Fuel stacking should be considered its own research problem. Clean-cooking transition research has for too long focused on other aspects of domestic household energy consumption, treating fuel stacking as ancillary to processes of transition. Our paper is the first to pivot this assumption by treating fuel stacking as a core research question when exploring existing household data. Through a pairing of qualitative insights with quantitative data analysis, we highlight the importance of understanding fuel stacking as a complex set of practices embedded within spaces, which have the potential to either facilitate or limit clean-cooking transitions.

This paper explores the range of factors associated with fuel stacking across national and regional urban contexts through a quantitative analysis of the World Bank's MTF data. The paper balanced this with a qualitative review of the wider clean-cooking discourse. In the presentation of findings and subsequent discussion, our paper identifies and proposes ways of exploring fuel stacking more holistically in future research related to clean-cooking transitions.

Existing literature, as cited earlier, suggests that an increase in the use of modern fuels relative to biomass at the household level is related to financial constraints, concerns of energy and food security, and a range of socio-cultural factors. While the analysis of MTF data above broadly shows how dynamics relevant to these factors differ across diverse urban contexts, the surveys are limited in their ability to isolate which factors (a) are most prominent in influencing continued fuel stacking, or (b) act as barriers to complete uptake of clean cooking.

The MTF surveys are a significant first step in linking energy access with cooking practices. This household-level data collection has allowed this research to investigate different types of fuel stacking, ranging from biomass-intensive practices to modern fuelintensive practices. This research reveals that the factors associated with the minimisation of biomass under fuel stacking do not necessarily lend themselves to explaining the elimination of biomass altogether. Although there is a place for survey data in helping us understand cooking transitions in any given context, this paper stresses the need for deeper research into understanding how and why households cook the way they do, and how fuel stacking is embedded within these decisions. Research needs to move beyond asking what fuels households stack, and instead interrogate how a household's cooking practices have changed over time to establish drivers of transition, which may be more closely related to social networks, local market availability, and media or advertising campaigns as opposed to economic or policy changes at the national level.

This paper argues that fuel stacking needs to be considered the norm, and thus worthy of attention as a core research problem. The clean-cooking sector must develop its interventions accordingly, and primarily through extensive engagement with local stakeholders and communities. The authors offer the following five recommendations:

1. Research into fuel stacking needs to be understood in relation to a broader context beyond cooking fuels and cooking practices. The choice of fuels is likely associated with the time pressures that results from the faster pace of contemporary urban life, as well as other financial burdens, including but not limited to rent and transport.

2. Clean-cooking technologies need to be assessed in relation to how households currently stack fuels and devices, how this has changed over time, and how households might prefer to combine fuels and devices in the future.

3. National research projects and interventions need to be supplemented with localised work in targeted cities and regions, to understand fuel stacking and cooking transitions in relation to more regional political, economic, and cultural contexts. This involves engaging a different set of stakeholders and communities than those involved in any existing clean-cooking programmes.

4. Further analysis of existing datasets is required to explore fuel-stacking practices in specific contexts. As in the case with the MTF surveys, fuel stacking is rarely an 
explicit research focus, but fuel-stacking parameters can be created using the data to explore the factors associated with these parameters.

5. Other attempts at categorising fuel stacking, such as the type and number of stoves and devices/appliances used, the size of the households, their employment status, the gender balance within the household, or their attitudes towards a particular fuel, would be equally valid. The authors encourage an in-depth analysis of such factors as pivotal to ongoing and future research.

Understanding the ways in which energy use, decision-making and risk perception are based on cultural context and intersect with social norms will provide insight into why households continue to rely on stacking. The World Health Organisation acknowledge that biomass will remain a part of the way people heat households and cook for years to come [5], and while the clean-cooking sector continues to work towards universal access to clean-cooking fuels and technologies, a greater emphasis is needed on what can ensure transitions are as successful and sustainable as possible. Our accounting of biomass and modern fuel intensity within stacking practices is unique in approach, paving the way for further locally embedded, mix-method research into the realities of fuel stacking. The authors of this paper argue for a deeper, more qualitatively driven, consideration of the changing nature of household structures and situated realities in urban environments to better understand, and address, the implications for transition pathways.

Author Contributions: Conceptualization, M.P.; methodology, M.P.; software, M.P.; formal analysis, M.P.; investigation, M.P., M.B.-T. and K.T.; resources, M.B.-T. and K.T.; data curation, M.P.; writingoriginal draft preparation, M.P., M.B.-T. and K.T.; writing-review and editing, M.B.-T., K.T. All authors have read and agreed to the published version of the manuscript.

Funding: The Modern Energy Cooking Services programme is funded by UK Aid (GB-GOV-1-300123).

Institutional Review Board Statement: Not applicable.

Informed Consent Statement: Not applicable.

Data Availability Statement: The data behind the results is available via the following links: https: // datacatalog.worldbank.org/dataset/cambodia-multi-tier-framework-mtf-survey-2018 (accessed on 5 April 2021) (Cambodia); https:/ / energydata.info/dataset/myanmar-multi-tier-framework-mtfsurvey (accessed on 5 April 2021) (Myanmar); https:/ / datacatalog.worldbank.org/dataset/zambiamulti-tier-framework-mtf-survey-0 (accessed on 5 April 2021) (Zambia).

Acknowledgments: The authors are grateful to ESMAP and the World Bank for making the data of the surveys available publicly. We would also like to express our deepest gratitude to Nigel Scott and Tom Jones (Gamos) for their valuable insights and commentary on the analysis of data.

Conflicts of Interest: The authors declare no conflict of interest. The funders had no role in the design of the study; in the collection, analyses, or interpretation of data; in the writing of the manuscript, or in the decision to publish the results.

\section{References}

1. Quinn, A.; Bruce, N.; Puzzolo, E.; Dickinson, K.; Sturke, R.; Jack, D.W.; Mehta, S.; Shankar, A.; Sherr, K.; Rosenthal, J. An analysis of efforts to scale up clean household energy for cooking around the world. Energy Sustain. Dev. 2018, 46, 1-10. [CrossRef]

2. ESMAP. The State of Access to Modern Energy Cooking Services; World Bank Group, Energy Sector Management Assistance Program (ESMAP): Washington, DC, USA, 2020. Available online: https://www.esmap.org/the-state-of-access-to-modern-energycooking-services (accessed on 24 May 2021).

3. World Health Organization. Burning Opportunity: Clean Household Energy for Health, Sustainable Development and Wellbeing of Women and Children; World Health Organization: Geneva, Switzerland, 2016. Available online: https://apps.who.int/iris/ bitstream/handle/10665/204717/9789241565233_eng.pdf?sequence=1\&isAllowed=y (accessed on 24 May 2021).

4. Williams, K.N.; Thompson, L.M.; Sakas, Z.; Hengstermann, M.; Quinn, A.; Díaz-Artiga, A.; Thangavel, G.; Puzzolo, E.; Rosa, G.; Balakrishnan, K.; et al. Designing a comprehensive behaviour change intervention to promote and monitor exclusive use of liquefied petroleum gas stoves for the Household Air Pollution Intervention Network (HAPIN) trial. BMJ Open 2020, 10 , e037761. [CrossRef] [PubMed]

5. World Health Organization. WHO Guidelines for Indoor Air Quality: Household Fuel Combustion. 2014. Available online: https: //www.who.int/airpollution/guidelines/household-fuel-combustion/IAQ_HHFC_guidelines.pdf (accessed on 7 July 2021). 
6. Is LPG Cheaper and Reliable? Available online: https://elstove.com/2019/05/29/is-lpg-cheaper-and-reliable/ (accessed on 7 July 2021).

7. Masera, O.M.; Saatkamp, B.D.; Kammen, D.M. From linear fuel switching to multiple cooking strategies: A critique and alternative to the energy ladder model. World Dev. 2000, 28, 2083-2103. [CrossRef]

8. Troncoso, K.; Castillo, A.; Masera, O.; Merino, L. Social perceptions about a technological innovation for fuelwood cooking: A case study in rural Mexico. Energy Policy 2007, 35, 2799-2810. [CrossRef]

9. Ruiz-Mercado, I.; Masera, O.; Zamora, H.; Smith, K.R. Adoption and sustained use of improved cookstoves. Energy Policy 2011, 39, 7557-7566. [CrossRef]

10. Puzzolo, E.; Pope, D.; Stanistreet, D.; Rehfuess, E.V.; Bruce, N.G. Clean fuels for resource-poor settings: A systematic review of barriers and enablers to adoption and sustained use. Environ. Res. 2016, 146, 218-234. [CrossRef]

11. Shankar, A.V.; Quinn, A.K.; Dickinson, K.L.; Williams, K.N.; Masera, O.; Charron, D.; Jack, D.; Hyman, J.; Pillarisetti, A.; Bailis, R.; et al. Everybody stacks: Lessons from household energy case studies to inform design principles for clean energy transitions. Energy Policy 2020, 141. [CrossRef] [PubMed]

12. Dave, R.; Keller, S.; Koo, B.B.; Fleurantin, G.; Portale, E.; Rysankova, D. Cambodia-Beyond Connections. Energy Access Diagonostic Report Based on Multi-Tier Framework; World Bank Group, Energy Sector Management Assistance Program (ESMAP): Washington, DC, USA, 2018. Available online: https:/ / openknowledge.worldbank.org/bitstream/handle/10986/29512/124490.pdf? sequence $=5 \&$ isAllowed $=y$ (accessed on 24 May 2021).

13. Koo, B.B.; Yoo, H.K.; Rysankova, D.; Portale, E. Myanmar-Beyond Connections: Energy Access Diagnostic Report Based on the Multi-Tier Framework; World Bank Group, Energy Sector Management Assistance Program (ESMAP): Washington, DC, USA, 2019. Available online: https:/ / openknowledge.worldbank.org/bitstream/handle/10986/32381/Myanmar-Beyond-ConnectionsEnergy-Access-Diagnostic-Report-Based-on-the-Multi-Tier-Framework.pdf?sequence=1\&isAllowed=y (accessed on 24 May 2021).

14. Luzi, L.; Lin, Y.; Koo, B.B.; Rysankova, D.; Portale, E. Zambia-Beyond Connections: Energy Access Diagnostic Report Based on the Multi-Tier Framework; World Bank Group, Energy Sector Management Assistance Program (ESMAP): Washington, DC, USA, 2019. Available online: http:/ / documents.worldbank.org/curated/en/477041572269756712/Zambia-Beyond-Connections-EnergyAccess-Diagnostic-Report-Based-on-the-Multi-Tier-Framework (accessed on 24 May 2021).

15. Tigabu, A.; Berkhout, F.; van Beukering, P. Development aid and the diffusion of technology: Improved cookstoves in Kenya and Rwanda. Energy Policy 2017, 102. [CrossRef]

16. Wang, Y.; Bailis, R. The revolution from the kitchen: Social processes of the removal of traditional cookstoves in Himachal Pradesh, India. Energy Sustain. Dev. 2015, 27, 127-136. [CrossRef]

17. Broto, V.C.; Arthur, M.d.F.S.R.; Guibrunet, L. Energy profiles among urban elite households in Mozambique: Explaining the persistence of charcoal in urban areas. Energy Res. Soc. Sci. 2020, 65. [CrossRef]

18. Gould, C.F.; Schlesinger, S.; Toasa, A.O.; Thurber, M.; Waters, W.F.; Graham, J.P.; Jack, D.W. Government Policy, Clean Fuel Access, and Persistent Fuel Stacking in Ecuador. Energy Sustain. Dev. 2018, 46, 111-122. [CrossRef]

19. Malakar, Y.; Greig, C.; van de Fliert, E. Resistance in rejecting solid fuels: Beyond availability and adoption in the structural dominations of cooking practices in rural India. Energy Res. Soc. Sci 2018, 46, 225-235. [CrossRef]

20. Malakar, Y. Studying household decision-making context and cooking fuel transition in rural India. Energy Sustain. Dev. 2018, 43, 68-74. [CrossRef]

21. Herington, M.J.; Lant, P.A.; Smart, S.; Greig, C.; van de Fliert, E. Defection, recruitment, and social change in cooking practices: Energy poverty through a social practice lens. Energy Res. Soc. Sci 2017, 34, 272-280. [CrossRef]

22. Rehfuess, E.A.; Puzzolo, E.; Stanistreet, D.; Pope, D.; Bruce, N.G. Enablers and barriers to large-scale uptake of improved solid fuel stoves: A systematic review. Environ. Health Perspect 2014, 122, 120-130. [CrossRef]

23. Jewitt, S.; Atagher, P.; Clifford, M. "We cannot stop cooking": Stove stacking, seasonality and the risky practices of household cookstove transitions in Nigeria. Energy Res. Soc. Sci 2020, 61, 101340. Available online: https:/ /www.sciencedirect.com/science/ article/pii/S2214629619304700\#bib0013 (accessed on 24 May 2021). [CrossRef]

24. Stanistreet, D.; Puzzolo, E.; Bruce, N.; Pope, D.; Rehfuess, E. Factors influencing household uptake of improved solid fuel stoves in low- and middle-income countries: A qualitative systematic review. Int J. Environ. Res. Pub. Health 2014, 11, 8228-8250.

25. ESMAP. Cooking with Electricity: A Cost Perspective; World Bank Group, Energy Sector Management Assistance Program (ESMAP): Washington, DC, USA, 2021; Available online: https://documents1.worldbank.org/curated/en/920661600750772102/pdf/ Cooking-with-Electricity-A-Cost-Perspective.pdf (accessed on 7 July 2021).

26. Troncoso, K.; Armendáriz, C.; Alatorre, S. Improved cookstove adoption and impact assessment: A proposed methodology. Energy Policy 2013, 62, 637-645. [CrossRef]

27. Winther, T. The Impact of Electricity: Development, Desires and Dilemmas; Berghahn Books: Oxford, UK, $2011 ;$ pp. $188-216$.

28. Jagadish, A.; Dwivedi, P. In the hearth, on the mind: Cultural consensus on fuelwood and cookstoves in the middle Himalayas of India. Energy Res Soc Sci 2018, 37, 44-51. [CrossRef]

29. Akintan, A.; Jewitt, S.; Clifford, M. Culture, tradition and taboo: Understanding the social shaping of fuel choices in Nigeria. Energy Res. Soc. Sci 2018, 40, 14-22. [CrossRef] 
30. Simmel, G. The Metropolis and Mental Life. In Classic Essays on the Culture of Cities; Sennet, Ed.; Appleton-Century-Crofts: New York, NY, USA, 1969; pp. 11-19. Available online: https://www.blackwellpublishing.com/content/bpl_images/content_store/ sample_chapter/0631225137/bridge.pdf (accessed on 24 May 2021).

31. Putnam, R. Social Capital: Measurement and Consequences. Available online: https://www.oecd.org/innovation/research/18 25848.pdf (accessed on 24 May 2021).

32. Bourdieu, P. Distinction: A Social Critique of the Judgement of Taste, 7th ed.; Routledge \& Kegan Paul: London, UK, 1984.

33. Georg, W.S.; Jones, P.H. What is a Sustainable Innovation? Cultural and Contextual Discoveries in the Social Ecology of Cooking in an African Slum. In Proceedings of the Ethnographic Praxis in Industry Conference, Minneapolis, MN, USA, 29 August-1 September 2016; Available online: https:/ /2016.epicpeople.org/ (accessed on 24 May 2021).

34. Kar, A.; Zerriffi, H. From cookstove acquisition to cooking transition: Framing the behavioural aspects of cookstove interventions. Energy Res. Soc. Sci 2018, 42, 23-33. [CrossRef]

35. Moses, N.D.; MacCarty, N.A. What makes a cookstove usable? Trials of a usability testing protocol in Uganda, Gautemala and the United States. Energy Res. Soc. Sci 2019, 52, 221-235. [CrossRef]

36. Ochieng, C.; Zhang, Y.; Nyabwa, J.K.; Otieno, D.I.; Spillane, C. Household perspectives on cookstove and fuel stacking: A qualitative study in urban and rural Kenya. Energy Sustain. Dev. 2020, 59, 151-159. [CrossRef]

37. Person, B.; Loo, J.D.; Cohen, A.L. It is good for my family's health and cooks food in a way that my heart loves: Qualitative findings and implications for scaling up an improved cookstove project in rural Kenya. Int J. Environ. Res. Pub. 2012, 9, 1566-1580. [CrossRef]

38. Barnes, D.; Khandker, S.R.; Samad, H.A. Energy poverty in rural Bangladesh. Energy Policy 2011, 39, 894-904. [CrossRef]

39. Catalán-Vázquez, M.; Fernández-Plata, R.; Martínez-Briseño, D.; Pelcastre-Villafuerte, B.; Riojas-Rodríguez, H.; Suárez-González, L.; Pérez-Padilla, R.; Schilmann, A. Factors that enable or limit the sustained use of improved firewood cookstoves: Qualitative findings eight years after an intervention in rural Mexico. PLOS ONE 2018, 13, e0193238.

40. Rosenthal, J.; Balakrishnan, K.; Bruce, N.; Chambers, D.; Graham, J.; Jack, D.; Kline, L.; Masera, O.; Mehta, S.; Ruiz Mercado, I.; et al. Implementation Science to Accelerate Clean Cooking for Public Health. Environ. Health Perspect. 2017, 125, A3-A7. [CrossRef] [PubMed]

41. Haysom, S.; McLaggan, M.; Kaka, J.; Modi, L.; Opala, K. The Charcoal Grey Market in Kenya, Ugands and South Sudan. 2021. Available online: https:/ / globalinitiative.net/wp-content/uploads / 2021/03/Black-Gold-The-charcoal-grey-market-in-KenyaUganda-and-South-Sudan.pdf-GITOC.pdf (accessed on 7 July 2021).

42. Ruiz-Mercado, I.; Masera, O. Patterns of sstove use in the context of fuel-device stacking: Rationale and implications. Ecohealth 2015, 12, 42-56. [CrossRef]

43. Price, M.; Jones, T.; Batchelor, S. Cambodia; Cooking Transitions: An Analysis of Multi-Tier Framework Data for Insights into Transitions to Modern Energy Cooking. 2020. Available online: https://mecs.org.uk/wp-content/uploads/2020/12/MTFCambodia-04112020.pdf (accessed on 24 May 2021).

44. Price, M.; Jones, T.; Scott, N. Myanmar; Cooking Transitions: An Analysis of Multi-Tier Framework Data for Insights into Transitions to Modern Energy Cooking. 2021. Available online: https://mecs.org.uk/wp-content/uploads/2021/04/Myanmarcooking-transitions.pdf (accessed on 24 May 2021).

45. Price, M.; Jones, T.; Scott, N. Zambia; Cooking Transitions: An Analysis of Multi-Tier Framework Data for Insights into Transitions to Modern Energy Cooking. 2021. Available online: https://mecs.org.uk/wp-content/uploads/2021/03/Zambia-cookingtransitions-MTF.pdf (accessed on 24 May 2021).

46. Price, M. Modern Energy Cooking Services: An Urban Perspective; MECS Programme Working Paper; MECS: Reading UK, 2021. Available online: https://mecs.org.uk/wp-content/uploads/2021/04/modern-energy-cooking-services-an-urban-perspective1.pdf (accessed on 24 May 2021).

47. Ruszczyk, H.A.; Rahman, M.F.; Bracken, L.J.; Sudha, S. Contextualizing the COVID-19 pandemic's impact on food security in two small cities in Bangladesh. Environ. Urban. 2021, 33. [CrossRef] [PubMed]

48. Ravindra, K.; Kaur-Sidhu, M.; Mor, S.; Chakma, J.; Pillarisetti, A. Impact of the COVID-19 pandemic on clean fuel programmes in India and ensuring sustainability for household energy needs. Environ. Int. 2021, 147. [CrossRef] [PubMed]

49. Oo, D. When the Lights Go Out in Myanmar. Asia Times. 13 April 2021. Available online: https://asiatimes.com/2021/04/whenthe-lights-go-out-in-myanmar / (accessed on 7 July 2021). 